\title{
Too Much of a Good Thing? On the Relationship Between CSR and Employee Work Addiction
}

\author{
Steven A. Brieger ${ }^{1,2} \cdot$ Stefan Anderer ${ }^{3,4} \cdot$ Andreas Fröhlich $^{3} \cdot$ Anne Bäro $^{3} \cdot$ Timo Meynhardt $^{2,3}$
}

Received: 25 May 2018 / Accepted: 28 February 2019 / Published online: 9 March 2019

(c) The Author(s) 2019

\begin{abstract}
Recent research highlights the positive effects of organizational CSR engagement on employee outcomes, such as job and life satisfaction, performance, and trust. We argue that the current debate fails to recognize the potential risks associated with CSR. In this study, we focus on the risk of work addiction. We hypothesize that CSR has per se a positive effect on employees and can be classified as a resource. However, we also suggest the existence of an array of unintended negative effects of CSR. Since CSR positively influences an employee's organizational identification, as well as his or her perception of engaging in meaningful work, which in turn motivates them to work harder while neglecting other spheres of their lives such as private relationships or health, CSR indirectly increases work addiction. Accordingly, organizational identification and work meaningfulness both act as buffering variables in the relationship, thus suppressing the negative effect of CSR on work addiction, which weakens the positive role of CSR in the workplace. Drawing on a sample of 565 Swiss employees taken from the 2017 Swiss Public Value Atlas dataset, our results provide support for our rationale. Our results also provide evidence that the positive indirect effects of organizational CSR engagement on work addiction, via organizational identification and work meaningfulness, become even stronger when employees care for the welfare of the wider public (i.e., the community, nation, or world). Implications for research and practice are discussed.
\end{abstract}

Keywords Corporate social responsibility $(\mathrm{CSR}) \cdot$ Public value $\cdot$ Work addiction $\cdot$ Organizational identification $\cdot$ Social identity theory $\cdot$ Social exchange theory

Steven A. Brieger

s.a.brieger@sussex.ac.uk

Stefan Anderer

st.anderer@gmail.com

Andreas Fröhlich

andreas.froehlich@hhl.de

Anne Bäro

anne.baero@hhl.de

Timo Meynhardt

timo.meynhardt@hhl.de

1 University of Sussex Business School, University of Sussex, Brighton, UK

2 Center for Leadership and Values in Society, University of St.Gallen, St.Gallen, Switzerland

3 Dr. Arend Oetker Chair of Business Psychology and Leadership, HHL Leipzig Graduate School of Management, Leipzig, Germany

4 Center for Advanced Studies in Management, HHL Leipzig Graduate School of Management, Leipzig, Germany

\section{Introduction}

Corporate social responsibility (CSR) - a concept whereby organizations "integrate social and environmental concerns in their business operations and in their interaction with their stakeholders on a voluntary basis" (European Commission 2001) - is receiving increased attention in practice. A growing number of organizations integrate social and environmental concerns into their operations, thereby aiming to contribute to the welfare of various stakeholders (including the environment) that go beyond narrow economic self-interest and legal requirements (Brieger et al. 2018; Dawkins et al. 2016; Kaplan and Kinderman 2017; McWilliams and Siegel 2001). Today, Fortune Global 500 firms devote over $\$ 15$ billion per year to CSR activities. In 2017, over $90 \%$ of the 250 largest companies in the world produced a CSR report to inform different stakeholders about their activities. That is up from 35\% in 1999 (Blasco and King 2017).

The business ethics literature on CSR outcomes at the micro level offers a very positive picture of the effects of 
CSR on employees, who form one of the most important stakeholder groups associated with an organization (Glavas and Godwin 2013; Glavas and Kelley 2014; Meynhardt et al. 2018). Various studies present evidence that employees who perceive themselves as working for a socially responsible organization show higher levels of organizational commitment, loyalty, trust, and engagement, and are also more satisfied with their jobs and lives in general (Brammer et al. 2007; De Roeck and Delobbe 2012; Glavas and Kelley 2014; Hansen et al. 2011; Kim et al. 2010; Meynhardt et al. 2018). While these findings create confidence that CSR has various positive effects on employees, the current debate neglects to recognize its potential negative outcomes at the micro level - the dark side of CSR. Thus, what is missing is a deeper understanding of how organizational CSR engagement may negatively affect employees and their attitudes, intentions, and behaviors.

This study problematizes the one-sided view of CSR as an exclusively positive factor, and aims to enlarge the debate on the multi-faceted consequences of CSR at the micro level by discussing the relationship between organizational CSR engagement and employee work addiction. Discussions about work addiction have worked their way into the broader public discourse, and their presence there indicates practical relevance. Work addiction is "the tendency to work excessively hard and being obsessed with work, which manifests itself in working compulsively" (Schaufeli et al. 2009, p. 322). Work addiction is considered an addiction because employees focus excessively on their work and fail to notice or enjoy other spheres in life, such as private relationships, spare-time activities and health (Andreassen et al. 2014). We argue that CSR is generally a positive force for employees, most significantly because companies that are committed to CSR protect their employees from working excessive hours. But we also suggest that CSR can unintentionally stimulate and cause employee work addiction. Specifically, we hypothesize that two mediators-organizational identification and work meaningfulness-play vital roles in the relationship between CSR and work addiction. We suggest that employees who work for socially responsible organizations tend to identify more strongly with their employing organization and perceive their work as more meaningful, which in turn motivates them to think continually about their work and to work excessively, unable to disengage from their work activities (Caesens et al. 2014; van Beek et al. 2011). We further hypothesize that the positive indirect effects of organizational CSR engagement on work addiction, via organizational identification and work meaningfulness, are even stronger if employees show awareness for public welfare. Figure 1 illustrates our research model.

To test our hypotheses, we draw on data for 565 employees polled by the Public Value Atlas Switzerland during 2017 (CLVS 2017), which has been conceptualized to create transparency regarding organizational contributions to the common good as perceived by the general public (Meynhardt 2009; Meynhardt et al. 2017). Our paper is structured as follows: First, we introduce an ethical analysis of CSR by debating the positive outcomes and potential risks of CSR for employees. Next, we present the concept of work addiction and discuss why it is a challenge for CSR in organizations. We then present our model and develop the hypotheses, and discuss the methodology in terms of sampling, data collection, and measures. This is followed by a description of our analysis and our main findings. Finally, the paper concludes with a discussion of the results, managerial implications, theoretical contributions, limitations, and suggestions for future research.

\section{The Positive Outcomes and Potential Risks of CSR for Employees}

Since CSR addresses a broad range of intra-organizational human resource management issues (e.g., fairness, diversity and empowerment, and health and safety), ethical analyses of CSR focusing on employees have provided important insights into how CSR influences employee outcomes (Aguinis and Glavas 2012; Du et al. 2015; Kim et al. 2010).

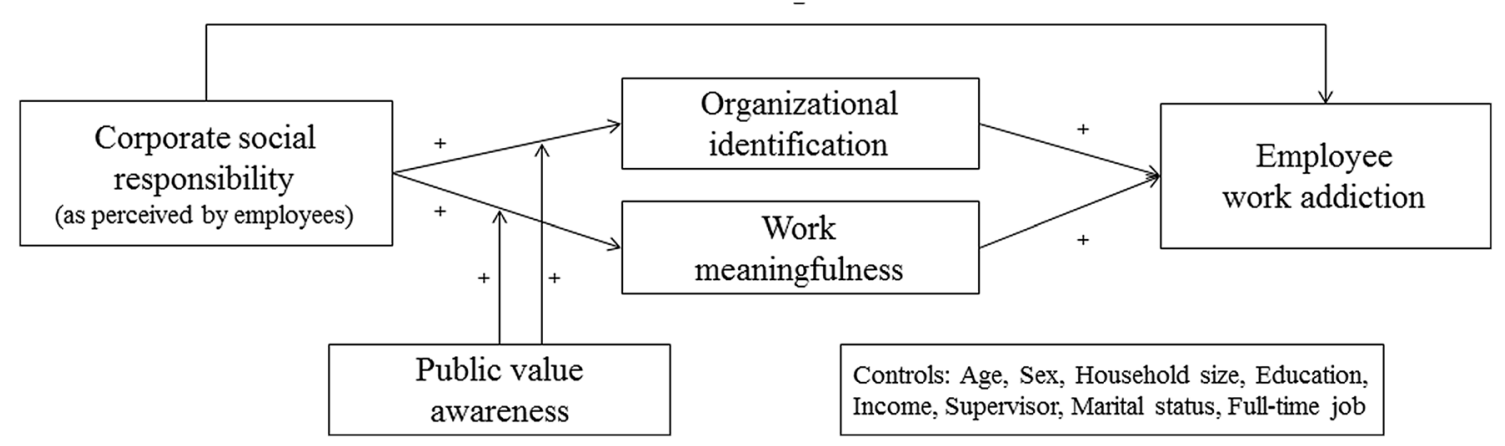

Fig. 1 Research model relating CSR and employee work addiction 
At present, the business ethics literature has drawn a very positive picture of CSR in the work context. It shows that employees who work for a socially responsible firm are more committed to, and better identify with, their employing organization. Additionally, the existing literature shows that they report higher levels of motivation, effort, organizational citizenship behavior, performance, and creative involvement at work (Brammer et al. 2015; Glavas and Piderit 2009; Newman et al. 2015). CSR practices also positively change the work environment because employees experience better relationships with their colleagues and supervisors within socially responsible organizations (Glavas and Piderit 2009; Jayasinghe 2016). Employees also tend to be more satisfied with their jobs and lives, and are less willing to quit their jobs, when working for a socially responsible organization (Glavas and Kelley 2014; Hansen et al. 2011; Meynhardt et al. 2018).

Without a doubt, the evidence of the positive effects of CSR on employees is very convincing. However, the existing business ethics literature neglects to investigate the potential risks that may coexist with the positive effects of CSR on employee outcomes (Rupp and Mallory 2015). The missing critical discussion of the downsides at the micro level can be explained by the fact that CSR is generally perceived as something good and desirable (Aguinis and Glavas 2012). While we generally do not wish to contradict this view, we would like to highlight three possible dangers that may arise when employees work in socially responsible companies: (1) self-sacrifice, (2) stagnation, and (3) self-righteousness. These three risks are established and frequently discussed in the field of work and organizational psychology (e.g., Abele et al. 2012; Barnett 2016; Lin-Hi and Müller 2013; Schabracq et al. 2003; Swann et al. 2014).

Self-sacrifice refers to voluntarily and excessively meeting the needs of other people at the expense of meeting one's own needs. It can occur when employees work very hard for their socially responsible business. Research suggests that work meaningfulness and identification with an organization are associated with work-life imbalances (Avanzi et al. 2012; Tokumitsu 2015). Because employees who work in organizations with strong records of CSR show higher levels of commitment, motivation and initiative at work, and tend to be happier with their jobs (Aguinis and Glavas 2017; Brammer et al. 2007; Farooq et al. 2014; Glavas and Kelley 2014), they may also tend to neglect their private lives and sacrifice their own well-being. Costas and Kärreman (2013) argue that CSR initiatives can be perceived as a form of intra-organizational management control that encourages identification with an attractive but idealized organizational image, thereby tying employees' career ambitions and sense of professional responsibility to the organization. Previous research also states that CSR increases employees' motivation to work harder and be more productive (Aguilera et al.
2007; Flammer 2015). In line with that, self-sacrifice can also result from heavy work obligations in an altruistic work environment in which employees work together for a greater common purpose (e.g., a healthy environment or societal welfare). If an organizational culture prioritizes hard work in order to achieve common goals, it may culminate in feelings of substantial work burden, overstress, or burnout among employees (Dempsey and Sanders 2010; Maes 2012).

Stagnation refers to the way in which organizational CSR activities and strategies may undermine employees' personal development, growth, and self-expression. Many organizations use CSR as a greenwashing tool and windowdressing intervention to gain legitimacy in order to maintain their license to operate (Delmas and Burbano 2011; Preuss 2012). In this way, symbolic CSR helps organizations create an idealized image of a socially responsible entity, even when irresponsible business practices and power imbalances are established (Perez-Batres et al. 2012). If CSR activities are used to disguise adverse externalities-such as low pay, highly unequal CEO-employee salary ratios, gender disparity, social class inequality, or work-life imbalances-those activities can have negative impacts on the workforce. Notably, they may contribute to the stagnation of employees' personal development and growth. But even if organizations take CSR very seriously and undertake substantive CSR actions-for example, by incorporating CSR into the business model-stagnation can affect employees when substantive CSR initiatives are external and resources are dedicated not to employees but rather to external stakeholders such as customers, community groups, or regulatory agencies (Farooq et al. 2017; Rupp and Mallory 2015). As a result, employees could be confronted with both stagnant incomes and stagnant skills acquisition, which could significantly reduce their future earning capacity, work-life balance and job skills over the long run. Previous literature provides evidence that the firm's social responsibility reputation is significantly associated with lower wages (Nyborg and Zhang 2013). People are often even willing to sacrifice some percentage of their pay to work for a socially responsible employer. Haski-Leventhal and Concato (2016) find that $14 \%$ of business students are willing to sacrifice more than $40 \%$ of their future income to work for an organization committed to CSR.

Self-righteousness can occur when employees identify strongly with their employing firm. Social identity theory suggests that individuals identify with entities in order to increase their self-worth and to distinguish themselves from the out-group (Ashforth and Mael 1989). Consequently, CSR may not only build bridges by strengthening diversity and cohesion, but may also create walls that separate individuals from one another, causing discrimination and other forms of exclusion built on moral high ground (thereby determining right from wrong behavior). Self-righteousness 
may also lead to the effect that employees are less willing to behave responsibly in non-work contexts if the organization's CSR engagement results in moral licensing. Moral licensing is "the psychological process that leads people to engage in morally questionable behavior after having previously engaged in socially desirable behavior" (Ormiston and Wong 2013, p. 865). Research indicates that people who recalled their own past moral actions subsequently show lower levels of prosocial intentions and behaviors (Blanken et al. 2015). Accordingly, if employees think they are behaving very morally by working for a responsible business, they might also think they have earned sufficient moral credit to achieve moral balance should they choose to engage in immoral non-work behavior (Mullen and Monin 2016; Sachdeva et al. 2009).

The previously outlined risks can occur in isolation, but may also be mutually dependent. For instance, as self-sacrificing employees tend to assign higher priority to intangible recompenses derived from serving others' needs while giving up tangible recompenses (such as monetary promotion or vacations) (Roh et al. 2016), self-sacrifice can undermine an employee's personal development and growth and result in both stagnant income and low skills acquisition and proficiency. Moreover, self-sacrifice can also affect self-righteousness in the form that employees who self-sacrifice via long hours and hard work in the service of others perceive themselves to be comparatively important to other human beings, thus creating a separation between themselves and out-group members who do not pursue an "important" job. In the following section, we develop and empirically test a model that links employee self-sacrifice caused by organizational CSR activities to employee work addiction. We discuss how a relationship between CSR and employee work addiction might be mediated by two central factorsorganizational identification and work meaningfulness-and how an employee's prosocial orientation further moderates the linkages.

\section{Work Addiction: The Best-Dressed Mental Health Problem in Business}

The concept of work addiction is well known under the label workaholism (a combination of work and alcoholism). The academic literature defines work addiction as "the compulsion or uncontrollable need to work incessantly" (Oates 1971 , p. 11). Workaholics become stressed if they are prohibited from working, leading them to ignore warnings to reduce their workload. Workaholics invest excessive time and energy in their work, work more than is demanded by implicit and explicit norms, and neglect other spheres of their life such as family, friendships, or health (Andreassen et al. 2012; Burke and Fiksenbaum 2009; Machlowitz 1980).
Accordingly, work addiction can have negative psychological, physical, and social effects for addicted employees, as well as for the people around them (Andreassen 2013). For instance, workaholics are often less happy, suffer from physical and mental health problems, report higher levels of exhaustion, and have more trouble sleeping (Burke 2000, 2001; Caesens et al. 2014; Kubota et al. 2010; Matsudaira et al. 2013; Schaufeli et al. 2009). Also, spouses of workaholics tend to report lower levels of happiness with their marriages, while children of workaholics tend to be more depressed (Carroll and Robinson 2000; Robinson et al. 2001).

Most definitions consider work addiction as a chronic behavioral pattern and a relatively stable individual characteristic (Andreassen et al. 2010). However, work addiction is not necessarily an inner impulse; it can also be driven by external forces. Organizational culture and norms, workplace peer pressure, and employee competition often play vital roles in the willingness to work excessively and compulsively. In fact, organizations worldwide tend to reward and encourage workaholic behaviors (Andreassen et al. 2010; Burke 2001). Regardless of whether in liberal, coordinated, mixed market, or even planned economies, employees working excessively have been highly appreciated and admired by their organizations. Since workaholics tend to outperform their peers and build up strong relationships during the long hours they work daily, organizations offer them more power and influence, and make it easier for them to climb the ladder. Also, the increased usage of digital technology in organizations (e.g., laptops and home computers, email communication, and mobile phones) serves to enable workaholic behaviors (Burke 2001). Flexible working schedules allow employees to work from home or elsewhere, leading to a blurring of the boundary between work and private life. Consequently, life in the digital age is increasingly characterized by the incursion of work into private life.

The heightened complexity of work as a consequence of new technologies and various other factors (such as globalization) blurs the lines of traditional labor. It affects more non-linear and decentralized forms of work, which demand new coordination mechanisms to orient and guide both individual and collective behavior. Current management models account for this by placing organizational and individual purpose at the center of a given model, which then serves as an attractor and motivator in the absence of top-down leadership (Kirchgeorg et al. 2017). In the absence of overarching standards in the workplace, and given the increased frequency of remote work, CSR as a corporate purpose stimulates organizational culture with a sense of shared higher ideals, goals, values, and norms that promote personal importance and responsibility, as well as collective commitment to common and meaningful goals (Chatman and Cha 2003; Costas and Kärreman 2013). Accordingly, a 
strong organizational culture with shared values and norms committed to CSR directs employees' attention towards organizational priorities and goals that guide their intentions, behaviors, and decision-making.

The prevalence of work addiction is difficult to detect due to a lack of reliable statistics. Porter (1996) claims that one in four employees is a workaholic. A study on work addiction found that approximately $10 \%$ of the general U.S. population may be workaholics (Andreassen 2013; Sussman et al. 2011). Sussman (2012) states that self-identified work addiction affects a third of the working population. Other studies report that the rate of work addiction is particularly high among college-educated people (approximately 8 to $17.5 \%$ ) and in professional occupations (approximately 23 to $25 \%$ ) such as lawyers, doctors, and psychologists (Doerfler and Kammer 1986; Sussman 2012). Recent research finds that work addiction is more widespread among management-level employees and in specific sectors like construction, communications, consultancy, and commercial trades (Andreassen et al. 2012; Taris et al. 2012).

\section{Development of Hypotheses}

\section{The Effect of Organizational CSR Engagement on Employee Work Addiction}

Our model seeks to create understanding about the impact of organizational CSR engagement on employee work addiction, as well as the underlying mechanisms. First, we argue that organizations with CSR policies and activities can help employees to balance demands at work and in their personal lives. Accordingly, we develop a resource-based perspective on CSR, arguing that in general CSR provides the means, capabilities, features, and controls that are beneficial for employees to avoid the symptoms of work addiction. Some of the most notable of those symptoms are an intense fear of failure at work, an obsession with work-related success, overwork, and feelings of guilt for not working enough. Thus, employees who work for socially responsible organizations should be less willing to free up more time to work or spend significantly more time working than initially intended.

The literature documents a positive impact of CSR on employment and working conditions (Aguinis and Glavas 2012; Jamali and Karam 2018). Organizations committed to CSR not only provide and promote occupational safety and health, human resource development, and diversity, but also work-life balance and support for working families. Work-life benefits like vacation, flex time, child and elderly care, leave (e.g., paternity), and limited work hours are common internal CSR activities. To promote work-life balance, many organizations monitor work hours, improve overtime supervision, and encourage the use of holidays. For instance, the Yamaha Group, a Japanese multinational corporation, highlights the promotion of work-life balance, including the reduction of total working hours, as an important CSR policy on their website (Yamaha 2017):

In order to reduce total working hours and prevent excessive work, Yamaha Corporation established guidelines for overtime through labor-management agreement. [...] We have programs such as "All Go Home at the Same Time Day," which encourage all employees to leave work on time, and programs to urge employees to fully use their paid leave days.

Accordingly, since socially responsible organizations follow strategies to reduce the risk of work addiction, employees should be less affected by work addiction and in turn put more priority on other important spheres of life, such as health or personal relationships (Andreassen et al. 2012). While the focus of internal CSR activities on work addiction is documented, as can be inferred from the above, there seems to be no evidence yet of how external CSR activities may affect work-life imbalances. We suggest that negative effects of external CSR on work addiction may also be observed, due to a potential negative effect of external CSR on internal competition. Theories on work orientation propose certain trade-offs between employees' pursuit of promotion and advancement and the pursuit of contributing to the common good and improving the world beyond individual self-interest (Wrzesniewski 2003). Hence, an organization's external CSR activities allow employees to become aware that there is something bigger than their individual welfare, such as the common good. This may promote a work environment that is less focused on individual performance and career progress, which, consequently, may increase teamwork and decrease internal competition and the likelihood of engaging in excessive work. Recent research shows that CSR positively affects team performance via team efficacy and team self-esteem (Lin et al. 2012). Based on the insight that organizations adopting CSR initiatives have a positive effect on employees, we hypothesize an inverse relationship between organizational CSR engagement and employee work addiction. Thus, our first hypothesis is as follows:

Hypothesis 1 Corporate social responsibility is negatively related to employee work addiction.

\section{The Mediating Role of Organizational Identification}

Although we argue that CSR is essentially a positive resource for employees, we also think that CSR can be a danger and increase employee work addiction. We think this is true primarily when employees develop a strong 
identification with their organization. An important conceptualization of identification is found in social identity theory (Blader and Tyler 2009; Tajfel and Turner 1986). According to social identity theory, members of social groups such as organizations strive to experience a positive distinctiveness through their affiliation with those organizations. People tend to identify with prestigious organizations to derive a positive social identity (Ashforth and Mael 1989), basking in a reflected glory that allows for more positive assessments. Organizations that contribute to a greater good allow for better self-perceptions of one's own group, as well as for positive expectations of others' perceptions of one's own group. The inherent positive value of external CSR activities and policies, which are concerned with caring for others and the environment and are thus a contribution to a greater good, can serve as a source of identification and positive self-image (Brammer et al. 2007; Glavas and Kelley 2014; Rosso et al. 2010). Research documents the positive effect of CSR on employees' identification with their employing firm (Brammer et al. 2015; Glavas and Godwin 2013; Kim et al. 2010). Even in industries with problematic images, such as the oil industry, employees who perceive a stronger CSR orientation of their employing organization report higher levels of organizational identification (De Roeck and Delobbe 2012).

Since employees tend to identify more closely with socially responsible organizations, we hypothesize that employees with higher levels of organizational identification are likely to exceed healthy levels of engagement in work, and are more likely to obtain higher levels of work addiction. This may be because employees with high levels of organizational identification are likely to have a self-image that is partially dependent on their organization's image, which in turn depends on the organization's success. Such employees, therefore, may have a stronger incentive to contribute to their organization's success by putting in above-average effort. Employees that show such a psychological reliance on their organization-in addition to a material dependency-may be more prone to work addiction.

Moreover, social exchange theory, which highlights the importance of reciprocity in intentions and behaviors, provides additional support for this argument (Farooq et al. 2014). According to social exchange theory, individuals tend to give back if they receive a benefit from another person. Accordingly, a socially responsible organization that gives priority to internal CSR, and thus cares for the wellbeing of its employees, may make employees feel obliged to reciprocate such voluntary socially responsible engagements. Consequently, employees with high organizational identification could feel a higher motivation for reciprocal actions and may thus be more willing to invest in the welfare of the organization through a strong focus on work. Also, if employees think they should give back to their socially responsible employing organization, they may have feelings of guilt and anxiety if they perceive themselves as not working hard enough for the welfare of that organization (Farooq et al. 2014). Employees with strong organizational identification may thus want to support their employing organization excessively.

As far as we know, there is only scant evidence of the relationship between organizational identification and employee work addiction. In an early study, Avanzi et al. (2012) present empirical support that strong organizational identification leads to a higher level of work addiction. Thus, we hypothesize that organizational identification is positively associated with employee work addiction. Besides, for the reasons mentioned earlier, organizational identification is likely to help explain the relationship between CSR engagement and employee work addiction, thereby acting as a suppressor variable that buffers the negative direct effect of CSR on employee work addiction. Therefore, we formulate our hypotheses as follows:

Hypothesis 2a Corporate social responsibility is positively related to organizational identification.

Hypothesis $\mathbf{2 b}$ Organizational identification is positively related to work addiction.

Hypothesis 2c Organizational identification positively mediates the negative relationship between corporate social responsibility and employee work addiction.

\section{The Mediating Role of Work Meaningfulness}

Work meaningfulness is defined as the value of a work goal or purpose judged in relation to an individual's ideals or standards (May et al. 2004; Spreitzer 1995). Aguinis and Glavas (2017) categorize meaningfulness as a fundamental human need. In a refined conception of meaningfulness, the authors describe the sense-making process in which the individual derives meaning from work as a multi-level construct comprising individual, organizational, and societal-level factors (e.g., national culture). These three factors determine whether employees actively make their work meaningful by applying different tactics, such as emphasizing (or not emphasizing) the positive aspects of work.

Variables such as work environment have not been studied much by researchers in the search for meaningfulness at work (Aguinis and Glavas 2017). Organizational CSR activities seem particularly promising as a source of meaningfulness for the members of an organization since they explicitly comprise caring for others and the environment (Glavas and Kelley 2014). Scholars argue that signaling the contribution to a greater good is a primary source of work meaningfulness (Glavas and Kelley 2014; Rosso et al. 2010). Glavas 
and Kelley (2014) find first empirical support for a positive association of CSR and work meaningfulness. Against this background, we hypothesize a positive influence of CSR on work meaningfulness.

So far, there is limited research on the work meaningfulness-work addiction linkage. Typically, the literature on meaningfulness assumes positive linear consequences, such as more meaningfulness is better than less or no meaningfulness at work. What we know from the literature is that work meaningfulness is an important determinant of engagement in work, and that its downside affects both employees and self-employed workers. For instance, May et al. (2004) show that, on a psychological level, meaningfulness is the most important antecedent of engagement in work. Moreover, their research reveals high and significant correlations of meaningfulness and psychological availability. In addition, the exploitative potential of work, primarily based on personal meaningfulness, is well documented in the artistic and creative industries (e.g., Duffy 2016; Tokumitsu 2015). Following this line of thought, we aim to test a more controversial perspective on the meaningfulness of work in the light of CSR measures. We assume that the personal meaningfulness of one's work environment partly explains excessive immersion in work and a compulsive drive to work while neglecting other important spheres of life. Consequently, we hypothesize that meaningfulness partially mediates the relationship between CSR and employee work addiction. Thus, our next hypotheses are as follows:

Hypothesis 3a Corporate social responsibility is positively related to work meaningfulness.

Hypothesis $\mathbf{3 b}$ Work meaningfulness is positively related to work addiction.

Hypothesis $3 c$ Work meaningfulness positively mediates the negative relationship between corporate social responsibility and employee work addiction.

\section{The Moderating Role of Public Value Awareness}

Public value awareness is based on Meynhardt's public value theory, which seeks to operationalize contributions to the common good through a psychology-based lens (Meynhardt 2009; Meynhardt and Gomez 2016). Public value awareness seeks to identify which publics or higher social unit individuals relate to, and to what extent individuals consider the welfare of these publics in their own intentions and behaviors (Meynhardt and Fröhlich 2019). Thus, public value awareness refers to the extent to which an individual considers specific social units and their basic needs as relevant in evaluations. As such, it also relates to an individual's emotional-motivational forces concerning the common good, and plays an integral part in an individual's evaluative, sense-making, and identity-shaping mechanisms. Individuals with higher levels of public value awareness for a particular higher social unit (such as their local community, their nation, or the world) are likely to care for the welfare of these units and derive a sense of meaning and identity from them.

We argue that public value awareness plays an essential moderating role in the positive relationships between CSR and both mediators organizational identification and work meaningfulness. We assume that the extent to which an employee shows awareness of a public's welfare affects the influence of CSR on the employee's level of organizational identification and work meaningfulness. If an organization adopts CSR policies, thereby caring for the environment and social well-being, it demonstrates care for the wider public - whether the local community, a nation, or the world as a whole. Accordingly, if employees have a high awareness of the welfare of the public and thus show a high prosocial orientation, a strong organization-person fit exists. This should result in positive outcomes concerning organizational identification and work meaningfulness (Meynhardt et al. 2018). Thus, we assume:

Hypothesis 4a The positive relationship between corporate social responsibility and organizational identification is positively moderated by public value awareness.

Hypothesis $4 \mathrm{~b}$ The positive relationship between corporate social responsibility and work meaningfulness is positively moderated by public value awareness.

Moreover, it can be expected that higher levels of public value awareness will also impact the mediators' indirect effects on employee work addiction, as also suggested by the evidence of the effects of similar forms of congruence on the relationship between organizational values and employee commitment (Boxx et al. 1991). As a result, employees with increased public value awareness should report higher levels of work addiction when they perceive themselves as working for a socially responsible firm. From this follows:

Hypothesis 5a The positive indirect effect of corporate social responsibility on work addiction via organizational identification is stronger if the level of public value awareness is higher.

Hypothesis $5 \mathbf{b}$ The positive indirect effect of corporate social responsibility on work addiction via work meaningfulness is stronger if the level of public value awareness is higher. 


\section{Method}

\section{Sample}

Data from the 2017 Swiss Public Value Atlas were used in this study. The Public Value Atlas seeks to provide transparency for the contributions of private and public organizations, non-governmental organizations, and public administrations to the common good (CLVS 2017; Meynhardt et al. 2018). Data were collected from a representative panel of Swiss citizens (based on age, gender, education, and geographic region) from the beginning of May 2017 until the end of June 2017 by intervista, a Swiss market research institute. Intervista provided information concerning 565 employees from the German-speaking part of Switzerland. The questionnaire was tested in a qualitative $(N=5)$ and quantitative pretest $(N=6)$ to check the adequacy of the study as well as the comprehensibility of the questions. Of the 565 employees between the ages of 19 and $75(M=42.82$ years, $S D=12.49), 46 \%$ were female and $54 \%$ male. Nearly $40 \%$ had tertiary education, and $68 \%$ worked full-time.

\section{Measures}

\section{Work Addiction}

Work addiction was assessed by five items from the Bergen Work Addiction Scale (Andreassen et al. 2012). The items were: "How often during the last year have you become stressed if you were not allowed to work?”, “...have you deprioritized hobbies, leisure activities or exercise because of your work?”, “...have you spent much more time working than initially intended?", "...have you been told by others to cut down on work and not listened to them?", and "...have you thought of how you could free up more time to work?" The items were rated on a five-point Likert scale (never, rarely, sometimes, often, and always). The Cronbach's alpha was 0.77 .

\section{Corporate Social Responsibility}

The independent variable was measured by Glavas and Kelley's (2014) Perceived Corporate Social Responsibility Scale. The scale consists of two four-item batteries covering social and environmental responsibilities of an organization. Examples of items include statements such as "Contributing to the well-being of employees is a high priority at my organization" "Contributing to the well-being of the community is a high priority at my organization," or "My organization takes great care that our work does not hurt the environment." Answers were given on a sevenpoint scale ( $1=$ strongly disagree to $7=$ completely agree $)$. The Cronbach's alpha for this scale was 0.91 .

\section{Organizational Identification}

Organizational identification reflects a cognitive relationship between employees and their organization, and was measured to assess employee-company identification (Kim et al. 2010). The scale comprises three items: "I feel strong ties with my company," "I experience a strong sense of belongingness to my company," and "I am part of my company." Answers were given on a seven-point scale $(1=$ strongly disagree to $7=$ completely agree). The Cronbach's alpha for this scale was 0.94 .

\section{Work Meaningfulness}

We applied Spreitzer's (1995) three-item meaning scale to assess work meaningfulness. The scale is a subscale of the psychological empowerment construct comprising the dimensions meaning, competence, self-determination, and impact. One item was adapted from the meaningfulness scale of Hackman and Oldham (1980). The purpose of the scale is to assess the employee's individual perception of the work environment. The items were: "The job I do is very important to me," "My job activities are personally meaningful to me," and "The work I do is meaningful to me." Answers were given on a seven-point scale $(1=$ strongly disagree to $7=$ completely agree). The Cronbach's alpha for this scale was 0.92 .

\section{Public Value Awareness}

Since individuals can relate to different levels of inclusion (e.g., work unit, local community, nation, or world), we used three subscales based on Meynhardt and Fröhlich (2019) that refer to a particular higher social unit (or public): local community, nation, and world. Each subscale consists of four items that are similar for each social unit. The items were: "I wonder if my behavior is decent for the [social unit: (1) world population, (2) people in Switzerland, (3) people in my community (e.g., town, municipality)]," “...is useful for the [respective social unit]," "....increases the quality of life of the [respective social unit]," and "...strengthens the cohesion of the [respective social unit]." Answers were given on a six-point scale ( $1=$ never to $6=$ always $)$, and the average score of the four items of each subscale is used. We labeled the three subscales "world value awareness," "nation value awareness," and "community value awareness." The 
Cronbach's alpha values were 0.93 for all three public value awareness scales.

\section{Control Variables}

We controlled for several respondent characteristics: respondent age (as a continuous variable), gender (male $=1$, female $=2$ ), education (nine groups, ranging from no schoolleaving certificate to high tertiary education), income (six groups, ranging from a gross monthly income of less than CHF 3000 to more than CHF 12,000), household size (number of members), full-time job (part-time job $=0$, full-time job $=1$ ), marital status (not in a relationship $=0$, in a relationship $=1$ ), and supervisor status (i.e., whether the respondent is a supervisor in the organization; no $=0$, yes $=1$ ).

\section{Results}

Two sets of analyses were conducted on the data. In the first step, we checked the potential for common method bias, since all our measures come from one single source. We employed Harman's one-factor test using a principal component analysis of all the items. The unrotated solution showed no evidence of one dominant common factor. Six factors had eigenvalues greater than 1 , with the first factor explaining only $28 \%$ of the total variance. In addition, we employed rotated factor loadings using promax rotation. The results show that the constructs load on different factors, confirming validity. Thus, common method bias does not present a significant threat to the study. Reliability was tested using estimates of Cronbach's alpha coefficients. All Cronbach's alpha coefficients (ranging from 0.77 to 0.94 ) were higher than the recommended value of 0.70 , thus showing high internal consistency and reliability (Nunnally 1978).

In the second step, the main hypotheses were tested. Table 1 presents the descriptive statistics and correlations of the variables used in this study. The results show that Swiss employees show moderate levels of work addiction $(M=2.49, S D=0.75)$ and tend to evaluate the CSR performance of their employing firms as relatively high $(M=4.65$, $S D=1.15$ ). Furthermore, above-average means were found for the mediators organizational identification $(M=5.10$, $S D=1.55)$ and work meaningfulness $(M=5.58, S D=1.27)$, and the moderator variables world value awareness $(M=3.22, S D=1.26)$, nation value awareness $(M=3.55$, $S D=1.20)$, and community value awareness $(M=3.58$, $S D=1.21$ ).

The results of the correlation matrix show that there are significant and positive bivariate relationships between work addiction and work meaningfulness $(r=0.11)$, supervisor $(r=0.18)$, full-time job $(r=0.11)$, and the three types of

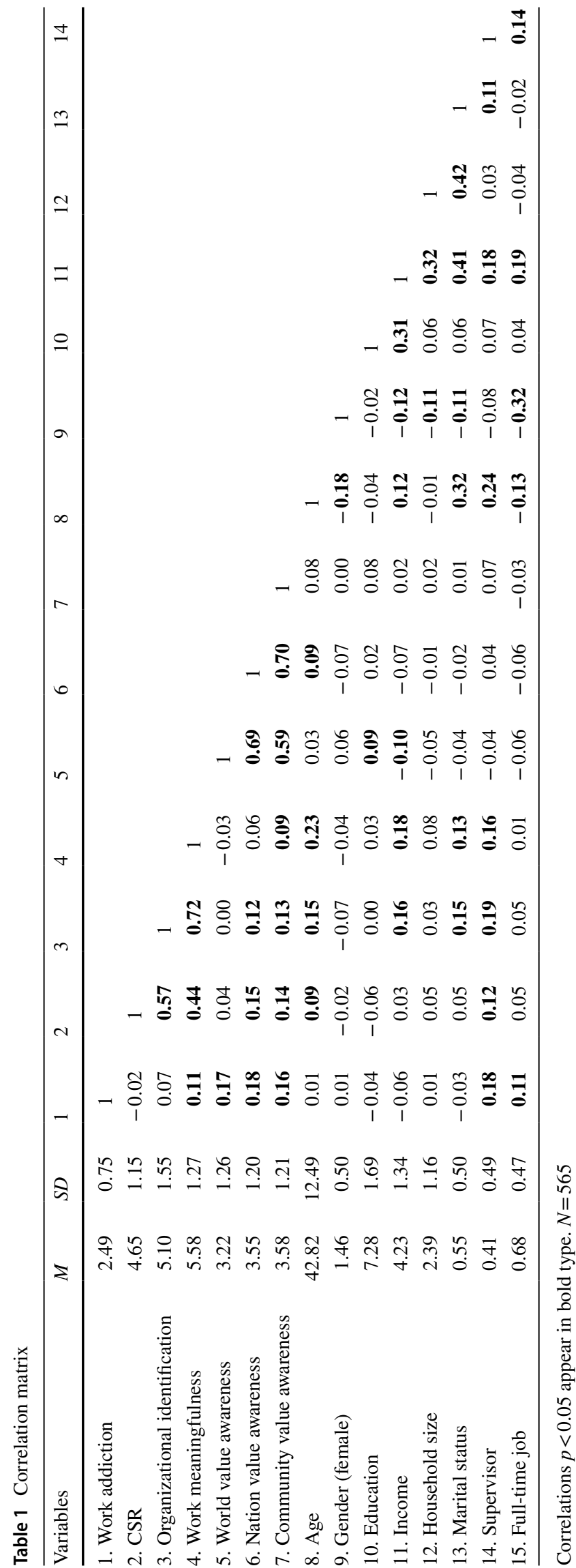


public value awareness: world ( $r=0.17)$, nation $(r=0.18)$, and community value awareness $(r=0.16)$. Furthermore, CSR shows positive associations with the mediators organizational identification $(r=0.57)$ and work meaningfulness ( $r=0.44$ ), public value awareness $(r=0.15$ for nation value awareness, and $r=0.14$ for community value awareness), and supervisor $(r=0.12)$. The mediators are strongly correlated with each other $(r=0.72)$, and both are significantly and positively related to community value awareness, income, marital status, and supervisor. Table 2 presents the results of the mediated regression analysis. We first ran a base model to test the effect of CSR on work addiction. The results of Model 1 indicate a negative association between CSR and work addiction $(b=-0.050 ; p<0.1)$. Accordingly, employees who work for a socially responsible business report lower levels of work addiction, thus supporting Hypothesis 1.

Hypothesis 2a was supported as the results of Model 2a show a positive association of CSR and organizational identification $(b=0.731 ; p<0.01)$. Model $2 \mathrm{~b}$ provides evidence for a positive relationship between organizational identification and work addiction $(b=0.056 ; p<0.05)$, indicating that employees who identify more closely with their employing organization tend to be more work addicted. Thus, Hypothesis $2 b$ was supported. We conducted a Sobel test to investigate the formal significance of a possible mediation effect. The result of the Sobel test reveals that organizational identification is a mediator of the effect of perceived CSR on work addiction $(\mathrm{z}=2.229 ; p<0.01)$. Thus, Hypothesis $2 \mathrm{c}$ was supported.

Moreover, Model 3a provides support for Hypothesis 3a. Employees who perceive their employing firm to be socially responsible show higher levels of work meaningfulness $(b=0.460 ; p<0.01)$. Also, a significant positive relationship between work meaningfulness and work addiction was found ( $b=0.092 ; p<0.01)$, thus providing support for Hypothesis $3 b$. Finally, support for Hypothesis $3 b$ was found, as the result of the Sobel test confirms a mediating role of work meaningfulness in the relationship between CSR and work addiction $(\mathrm{z}=3.202 ; p<0.01)$.

The results indicate that both mediators act as suppressor variables, buffering the negative direct effect of CSR on employee work addiction. While the direct effect of CSR on work addiction is negative $(b=-0.091 ; p<0.01$

Table 2 Results for mediation effects

\begin{tabular}{|c|c|c|c|c|c|}
\hline Dependent variable & Work addiction [1] & $\begin{array}{l}\text { Org. identifica- } \\
\text { tion [2a] }\end{array}$ & Work addiction [2b] & $\begin{array}{l}\text { Work meaning- } \\
\text { fulness [3a] }\end{array}$ & Work addiction [3b] \\
\hline \multicolumn{6}{|l|}{ Independent variable } \\
\hline CSR & $-0.050 *$ & $0.731 * * *$ & $-0.091 * * *$ & $0.460 * * *$ & $-0.092 * * *$ \\
\hline \multicolumn{6}{|l|}{ Mediators } \\
\hline Organizational identification & & & $0.056 * *$ & & \\
\hline Work meaningfulness & & & & & $0.092 * * *$ \\
\hline \multicolumn{6}{|l|}{ Moderators } \\
\hline World value awareness & $-0.050 *$ & $0.731 * * *$ & $-0.091 * * *$ & -0.076 & 0.051 \\
\hline Nation value awareness & 0.044 & -0.086 & 0.048 & 0.002 & 0.067 \\
\hline Community value awareness & 0.067 & 0.050 & 0.064 & 0.059 & 0.027 \\
\hline \multicolumn{6}{|l|}{ Controls } \\
\hline Age & -0.000 & 0.004 & -0.000 & $0.018 * * *$ & -0.002 \\
\hline Gender (female) & 0.099 & -0.096 & 0.104 & 0.056 & 0.094 \\
\hline Education & -0.021 & 0.003 & -0.021 & 0.021 & -0.023 \\
\hline Income & $-0.055^{* *}$ & $0.120 * *$ & $-0.061 * *$ & $0.115^{* * *}$ & $-0.065^{* *}$ \\
\hline Household size & 0.039 & $-0.100 *$ & 0.045 & 0.018 & 0.037 \\
\hline Marital status & -0.019 & $0.253^{*}$ & -0.033 & -0.028 & -0.016 \\
\hline Supervisor & $0.298 * * *$ & $0.241 * *$ & $0.285 * * *$ & 0.114 & $0.288 * * *$ \\
\hline Full-time job & $0.224 * * *$ & -0.035 & $0.226 * * *$ & -0.021 & $0.226 * * *$ \\
\hline Constant & $1.883 * * *$ & $0.997 *$ & $1.827 * * *$ & $1.950 * * *$ & $1.703 * * *$ \\
\hline$R^{2}$ & 0.102 & 0.367 & 0.110 & 0.259 & 0.119 \\
\hline$F$ value & $5.197 * * *$ & $26.70 * * *$ & $5.236 * * *$ & $16.05^{* * *}$ & $5.748 * * *$ \\
\hline Sobel test $(z)$ & & & $2.229 * * *$ & & $3.202 * * *$ \\
\hline Indirect effect & & & $0.041 * *$ & & $0.042 * * *$ \\
\hline
\end{tabular}

$N=565$

Significant levels: $* p<0.1 ; * * p<0.05 ; * * * p<0.01$ 
for the organizational identification model, and $b=-0.092$; $p<0.01$ for the work meaningfulness model), the indirect effects of CSR on work addiction via organizational identification $(b=0.041 ; p<0.05)$ and work meaningfulness $(b=0.042 ; p<0.01)$ are positive, providing evidence for a so-called inconsistent mediation (or suppression effect). In other words, employees who work for a socially responsible business report lower levels of work addiction. However, at the same time, employees who work for a socially responsible firm also identify more strongly with their employing firm and perceive their work as more meaningful, which in turn motivates them to assign higher priority to their work. In consequence, increases in organizational identification and work meaningfulness weaken the positive role of CSR. However, the negative direct effects of CSR on work addiction are still higher than the indirect effects through which CSR positively affect work addiction via the mediators. This indicates that CSR still weakens employee work addiction, even if the impact is smaller than it would be if employees were not personally and emotionally attached by the CSR commitment of their employing firms. Since the direct and indirect effects cancel each other out, we also observe that the direct effects in the Models $2 b$ and $3 b$ are even larger than the total effect of CSR on employee work addiction in Model 1. Thus, consistent with an overall suppression effect, the negative effect of CSR on work addiction is enhanced when we control for organizational identification and work meaningfulness, respectively.

A further post hoc analysis was carried out to identify differences between employees who report above-average and below-average levels of work addiction. The full results are available from the authors upon request. We find evidence that our hypotheses are fully confirmed only for employees who report above-average levels of work addiction. This is plausible because employees who are not susceptible to work addiction should tend to be less influenced in their workaholism by CSR, organizational identification, or work meaningfulness.

Tables 3 and 4 present the results of the moderation analysis and the moderated mediation analysis. We first tested whether the interaction of CSR and public value awareness is significant in predicting organizational identification and work meaningfulness. The results in Table 3 reveal that both world and nation value awareness amplify

Table 3 Results for moderation effects

\begin{tabular}{|c|c|c|c|c|c|c|}
\hline \multirow[t]{2}{*}{ Dependent variable } & \multicolumn{3}{|c|}{ Organizational identification } & \multicolumn{3}{|c|}{ Work meaningfulness } \\
\hline & {$[4 a]$} & {$[4 \mathrm{~b}]$} & {$[4 c]$} & {$[5 \mathrm{a}]$} & {$[5 b]$} & {$[5 \mathrm{c}]$} \\
\hline \multicolumn{7}{|l|}{ Independent variable } \\
\hline CSR & $0.482 * * *$ & $0.464 * * *$ & $0.509 * * *$ & 0.133 & 0.132 & $0.286^{* *}$ \\
\hline \multicolumn{7}{|l|}{ Moderators } \\
\hline World value awareness & $-0.446^{* *}$ & -0.087 & -0.090 & $-0.548 * * *$ & -0.077 & -0.079 \\
\hline Nation value awareness & 0.051 & -0.303 & 0.044 & 0.003 & $-0.430 * * *$ & -0.002 \\
\hline Community value awareness & 0.073 & 0.073 & -0.204 & 0.051 & 0.052 & -0.161 \\
\hline \multicolumn{7}{|l|}{ Interactions } \\
\hline \multicolumn{7}{|l|}{ CSR } \\
\hline$\times$ World value awareness & $0.076^{* *}$ & & & $0.100 * * *$ & & \\
\hline$\times$ Nation value awareness & & $0.075^{* *}$ & & & $0.092 * * *$ & \\
\hline$\times$ Community value awareness & & & 0.061 & & & 0.047 \\
\hline \multicolumn{7}{|l|}{ Controls } \\
\hline Age & 0.004 & 0.004 & 0.004 & $0.017 * * *$ & $0.017 * * *$ & $0.017 * * *$ \\
\hline Gender (female) & -0.086 & -0.097 & -0.092 & 0.070 & 0.055 & 0.059 \\
\hline Education & 0.001 & 0.004 & 0.004 & 0.018 & 0.021 & 0.021 \\
\hline Income & $0.125 * * *$ & $0.124 * * *$ & $0.120 * *$ & $0.122 * * *$ & $0.120 * * *$ & $0.115^{* * *}$ \\
\hline Household size & $-0.101 *$ & $-0.103^{*}$ & $-0.096 *$ & 0.016 & 0.015 & 0.021 \\
\hline Marital status & $0.245^{*}$ & $0.247 *$ & $0.245^{*}$ & -0.039 & -0.036 & -0.034 \\
\hline Supervisor & $0.247 * *$ & $0.239 * *$ & $0.240 * *$ & 0.121 & 0.111 & 0.112 \\
\hline Full-time job & -0.060 & -0.059 & -0.056 & -0.054 & -0.051 & -0.038 \\
\hline Constant & $2.236^{* * *}$ & $2.336 * * *$ & $2.086^{* *}$ & $3.575^{* * *}$ & $3.591 * * *$ & $2.801 * * *$ \\
\hline$R^{2}$ & 0.373 & 0.372 & 0.370 & 0.272 & 0.270 & 0.261 \\
\hline$F$ value & $25.17 * * *$ & $25.13^{* * *}$ & $24.92 * * *$ & $15.86^{* * *}$ & $15.66^{* * * *}$ & $15.00 * * *$ \\
\hline
\end{tabular}

$N=565$

Significant levels: $* p<0.1 ; * * p<0.05 ; * * * p<0.01$. 
Table 4 Results for conditional indirect effects

\begin{tabular}{|c|c|c|c|c|c|c|c|c|}
\hline \multirow[t]{2}{*}{ Mediator } & \multirow[t]{2}{*}{ Moderator } & \multirow[t]{2}{*}{ Level } & \multicolumn{6}{|c|}{ Dependent variable: work addiction } \\
\hline & & & Indirect effect & SE & $z$ & $P>|z|$ & LL 95\% CI & UL $95 \%$ CI \\
\hline \multirow[t]{3}{*}{ Organizational identification } & \multirow[t]{3}{*}{ World value awareness } & Low $(-1 S D)$ & 0.033 & 0.016 & 2.11 & 0.035 & 0.002 & 0.064 \\
\hline & & Middle $(M)$ & 0.038 & 0.018 & 2.14 & 0.033 & 0.003 & 0.073 \\
\hline & & $\operatorname{High}(+1 S D)$ & 0.043 & 0.020 & 2.13 & 0.033 & 0.003 & 0.083 \\
\hline \multirow[t]{3}{*}{ Organizational identification } & \multirow[t]{3}{*}{ Nation value awareness } & Low $(-1 S D)$ & 0.036 & 0.016 & 2.25 & 0.024 & 0.005 & 0.067 \\
\hline & & Middle $(M)$ & 0.041 & 0.018 & 2.29 & 0.022 & 0.006 & 0.076 \\
\hline & & $\operatorname{High}(+1 S D)$ & 0.046 & 0.020 & 2.28 & 0.023 & 0.006 & 0.086 \\
\hline \multirow[t]{3}{*}{ Organizational identification } & \multirow[t]{3}{*}{ Community value awareness } & Low $(-1 S D)$ & 0.037 & 0.016 & 2.25 & 0.025 & 0.005 & 0.069 \\
\hline & & Middle $(M)$ & 0.041 & 0.018 & 2.28 & 0.022 & 0.006 & 0.076 \\
\hline & & $\operatorname{High}(+1 S D)$ & 0.045 & 0.020 & 2.27 & 0.023 & 0.006 & 0.084 \\
\hline \multirow[t]{3}{*}{ Work meaningfulness } & \multirow[t]{3}{*}{ World value awareness } & Low $(-1 S D)$ & 0.029 & 0.010 & 2.77 & 0.006 & 0.008 & 0.049 \\
\hline & & Middle $(M)$ & 0.039 & 0.013 & 3.05 & 0.002 & 0.014 & 0.065 \\
\hline & & $\operatorname{High}(+1 S D)$ & 0.050 & 0.017 & 3.03 & 0.002 & 0.018 & 0.083 \\
\hline \multirow[t]{3}{*}{ Work meaningfulness } & \multirow[t]{3}{*}{ Nation value awareness } & Low $(-1 S D)$ & 0.032 & 0.011 & 2.97 & 0.003 & 0.011 & 0.054 \\
\hline & & Middle $(M)$ & 0.043 & 0.013 & 3.25 & 0.001 & 0.017 & 0.068 \\
\hline & & $\operatorname{High}(+1 S D)$ & 0.053 & 0.016 & 3.23 & 0.001 & 0.021 & 0.085 \\
\hline \multirow[t]{3}{*}{ Work meaningfulness } & \multirow[t]{3}{*}{ Community value awareness } & Low $(-1 S D)$ & 0.037 & 0.012 & 3.02 & 0.003 & 0.013 & 0.061 \\
\hline & & Middle $(M)$ & 0.042 & 0.013 & 3.24 & 0.001 & 0.017 & 0.068 \\
\hline & & $\operatorname{High}(+1 S D)$ & 0.047 & 0.015 & 3.18 & 0.001 & 0.018 & 0.077 \\
\hline
\end{tabular}

$L L$ lower limit of confidence interval (CI), $U L$ upper limit of $\mathrm{CI}$

$N=565$

the positive effect of CSR on organizational identification $(b=0.076 ; p<0.05$ for world value awareness, and $b=0.075 ; p<0.05$ for nation value awareness), and work meaningfulness $(b=0.100 ; p<0.01$ for world value awareness, and $b=0.092 ; p<0.01$ for nation value awareness), respectively. However, the interaction terms for CSR with community value awareness were non-significant in predicting organizational identification and work engagement. Therefore, Hypotheses $4 \mathrm{a}$ and $4 \mathrm{~b}$ were only partially supported.

Finally, we tested the moderated mediation Hypotheses $5 \mathrm{a}$ and $5 \mathrm{~b}$. We found that the indirect effect of CSR on work addiction via each mediator differs for employees across low and high levels of public value awareness. The results of Table 4 indicate that for organizational identification and work meaningfulness, the conditional indirect effect is positive and different from zero for all levels of public value awareness. However, that effect is stronger at higher levels of world, nation, and community value awareness. This indicates that the negative effect of CSR on work addiction is more strongly buffered if the employee gives strong priority to the welfare of the wider public (i.e., local community, nation, or world), thus having a strong fit with the socially responsible employing organization. A strong public value awareness amplifies the positive impact of CSR on each mediator, by which work addiction levels begin to rise even more. To gain a better understanding of the nature of these significant interactions, the corresponding graphs are plotted in Fig. 2. Thus, Hypotheses 5a and 5b were supported.

\section{Discussion and Conclusion}

\section{Discussion of the Findings}

The existing business ethics literature has predominantly focused on the positive outcomes of CSR for stakeholders. In the past, this has been primarily with respect to external stakeholders. Recently, it has paid increasing attention to internal stakeholders (Glavas and Kelley 2014; Meynhardt et al. 2018). Recent research investigating the influence of CSR on employee attitudes, intentions, and behaviors highlights the positive effects of CSR on employee job and life satisfaction, organizational identification, work engagement, and proactive work behavior (Glavas and Piederit 2009; Glavas and Kelley 2014; Meynhardt et al. 2018). However, the current debate fails to recognize the potential dark side of CSR at the micro level. Hitherto, negative outcomes of CSR were mostly reduced to the macro level. For instance, some studies suggest a negative effect of CSR on financial performance (e.g., Makni et al. 2009; Mittal et al. 2008). Moreover, while Bocquet et al. $(2013,2017)$ report a positive effect of strategic CSR on a firm's innovative capacity, they have also shown that 

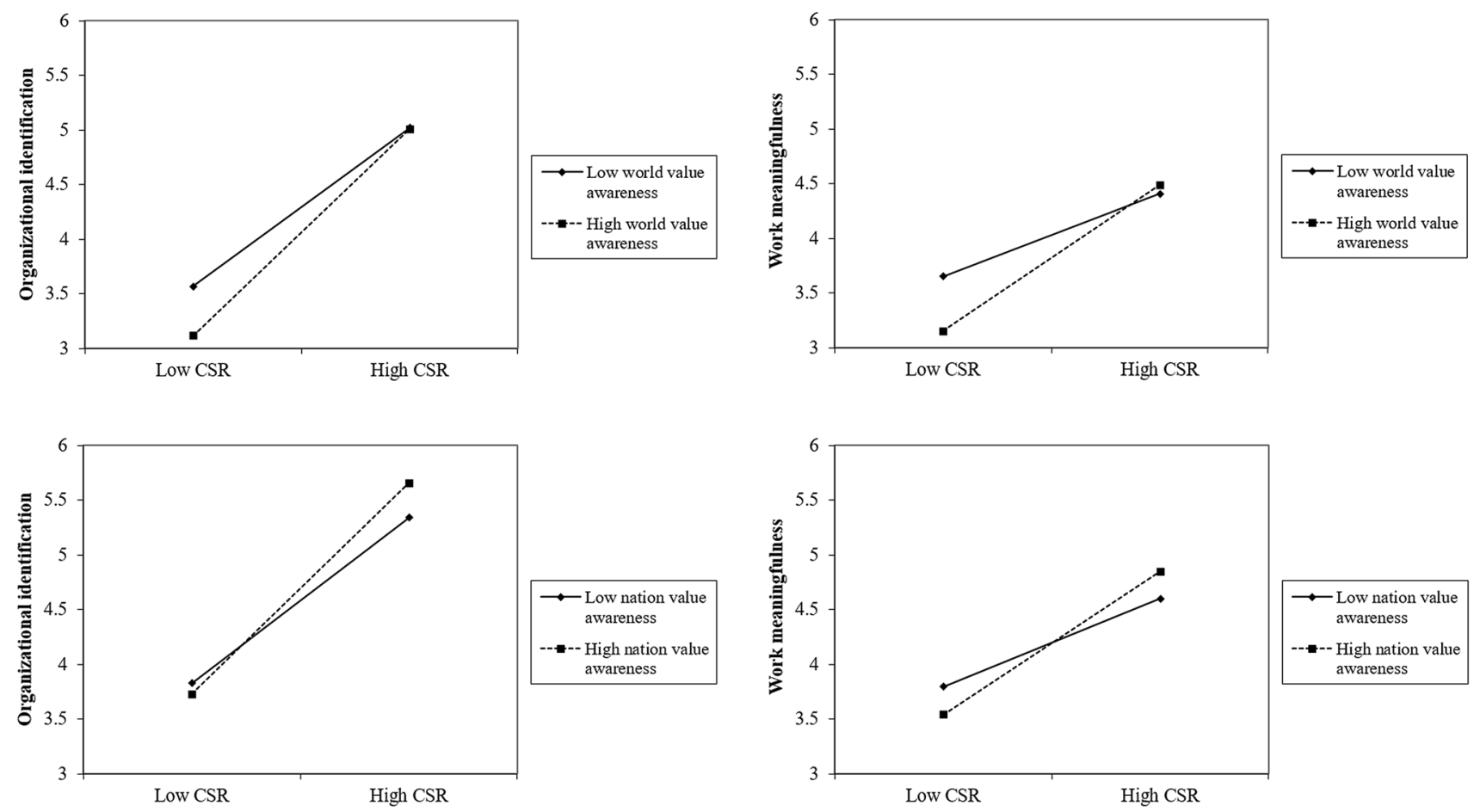

Fig. 2 Moderating effects on the CSR-organizational identification and CSR-work meaningfulness relationships

responsive CSR engagement, which tends to be disconnected from a firm's overall strategy, constitutes a barrier to innovation. Additionally, CSR is also critically discussed as a source of capitalism's legitimacy and preservation. For example, Banerjee (2008) sees CSR as an ideological movement intended to consolidate and legitimize the power of large corporations. As CSR helps companies gain legitimacy and avoid criticism, it is used by companies to preempt government regulation and control (Kinderman 2011). With this study, we complement the debate around the dark side of CSR by focusing on the downsides at the micro level. We argue that CSR activities should not be seen solely as a positive force, but also as a potential threat to employees and their social systems. Our model allows for a more balanced perspective and hints to the downsides and risks of CSR. Our hypotheses reflect the dichotomous effects that can be evoked by organizational practices aiming to protect the environment and social well-being.

In our first step, we hypothesized that CSR could be classified as a job resource that helps employees to achieve their work goals, reduce job demands, and stimulate their personal growth and development (Schaufeli and Taris 2014). We argue that organizations that promote CSR also support policies and mechanisms to prevent work overload and counter work cultures that value work addiction. Indeed, the significant negative direct effect of perceived CSR on employee work addiction supports our view. It indicates that employees who experience a CSR culture in their organization also tend to have a healthier and more balanced attitude towards work and are more likely to deprioritize other spheres of life.

In our second step, we discuss why the negative effect of CSR on employee work addiction is buffered when employees identify with their employing organization and perceive their work to be meaningful. Drawing on social identity theory, we suggest that employees tend to show stronger organizational identification and perceive their work as meaningful, worthwhile, and relevant when their employing organizations are willing to contribute to the common good. In turn, if employees create strong relationships with their organization and work, they may be more likely to work harder and to think continually about both; in this sense, CSR may contribute to the development of a strong emotional linkage. Thus, we expect organizational identification and work meaningfulness to have mediating roles. The study's results support the proposed mediating roles of organizational identification and work meaningfulness. We find that perceived CSR positively affects organizational identification and work meaningfulness, and both mediators in turn positively affect employee work addiction. Since the direct effect of CSR on work addiction is negative, while the indirect effect of CSR on work addiction via each mediator is positive, the effects tend to cancel each other out. In other words, organizational identification and work meaningfulness buffer the negative impact of CSR on employee work 
addiction. Organizations adopting CSR strategies can thus unintentionally stimulate and cause employee work addiction, harming the well-being of employees, their family members, and their friends. This might counteract the positive intentions of socially responsible organization.

Finally, in our third step, we hypothesize a positive moderating effect of an employee's public value awareness on the relationship between perceived CSR and each mediator. We present empirical evidence that an employee's relatedness to and concern for the welfare of higher social units amplifies the positive influence organizational CSR has on the employee's identification with the employing organization and their perception of having meaningful work. This organization-person fit - when both the employing organization and the employee care for the common good-also has, in turn, consequences for the extent to which employees are willing to work excessively and neglect other spheres of life. As the study's results reveal, the indirect effect of organizational CSR engagement on work addiction via organizational identification and work meaningfulness is stronger at higher levels of employee public value awareness, implying that the negative effect of organizational CSR engagement on work addiction will be significantly absorbed if both the employee and the employing firm give priority to social well-being and environmental protection.

Overall, the results show that CSR is a positive force for employees but not as impactful as typically anticipated. Today, individuals and organizations are expected to behave in a socially responsible manner. Caring for the greater good is fashionable for many valid reasons. People recognize that social and environmental problems-whether inequality, poverty, lack of educational opportunities, or ecological destruction-have to be addressed (Brieger 2018; Schaltegger and Hörisch 2017). However, an intense focus on other people's welfare can, as our results show, lead to an unintended situation in which employees neglect both their own lives and the lives of their families and friends. Undoubtedly, CSR serves as a resource for the employee, as companies that are committed to CSR protect their employees from working excessive hours and care for their well-being. But employees who derive more meaningfulness from their work and identify more strongly with their employing organization could benefit less from this resource over the long run.

Moreover, CSR activities in particular can damage employee well-being if a culture is built on the idea that the concern for others outweighs everything else-including the needs of employees themselves. This expands the conventional lines of theoretical reasoning. Social identity theory suggests that identification is conditional upon the internalization of group membership, and members who identify with a group tend to behave in accordance with the group's norms and values (Ashforth and Mael 1989; Tajfel and Turner 1986). In the process of internalization, individuals take on and self-regulate group values and behavioral norms (Deci and Ryan 2000). They identify with a group, and the group becomes a significant part of their self-concept. Internalization literature associates positive effects with internalization, such as greater persistence, more positive self-perception and self-evaluation, better quality of engagement, and intrinsic motivation (Ryan and Deci 2000). This study's findings call for a more nuanced view of the effects of internalization of group norms and values. Our results suggest that the stronger the internalization of the organization's values into one's own self-concept, the more willing one is to act in accordance with the goals of an organization while devaluing other spheres of life. Some scholars call this identity tension a "we versus me" phenomenon, in which there is a major shift in identity towards a social group (e.g., Kreiner et al. 2006). Therefore, a strong ethical fit of employee and organization has unintended effects on employees, as employees with strong prosocial values who work for a socially responsible firm show higher levels of identification with their employing firm and perceive their work as more meaningful. Interestingly, because of the strong organizational identity and the perception that they are engaging in something meaningful, socially oriented employees may not even realize that they are working excessively and neglecting other spheres in life; instead, they are more motivated at work, hold positive self-evaluations, and report higher levels of job and life satisfaction.

Our study also contributes to a better understanding of social exchange theory in the CSR discourse. If an employee working for a socially responsible firm can increase his or her perceived self-worth, experience strong support from co-workers, and feel favorably treated by his or her socially responsible employer, then he or she reciprocates by giving back. Reciprocity should be even stronger when a socially oriented employee works for a socially responsible organization. This may result in favorable work attitudes, organizational commitment and support, organizational citizenship behaviors, and higher job performance (Brammer et al. 2007; Cropanzano and Rupp 2008). However, as our results suggest, there are unintended downsides of reciprocity if heightened identification with the employer and the perception of meaningful work stimulate employees to work harder.

\section{Managerial Implications}

The results of this study offer important implications for management practice. First of all, the findings should not be interpreted as evidence that CSR activities harm employees, or that organizations should invest less in (or stop) their CSR engagement. Not only can CSR reduce the risk of employee work addiction, as this study shows, but it is also associated with multiple positive employee outcomes, such as job and life satisfaction, commitment, work engagement, and 
performance (Aguinis and Glavas 2017; Brammer et al. 2015; Meynhardt et al. 2018; Newman et al. 2015). Moreover, at the macro level, organizational contributions to more sustainable development are not only desirable but necessary in the face of today's worldwide environmental and social problems (Hörisch et al. 2017). In light of all the positive effects of CSR on both the micro and macro levels, it seems wise for organizations to engage in CSR activities.

However, our research also emphasizes that organizations should consider the positive effects of CSR on their workforce with care, as there may also be unintended negative consequences. When perceived CSR engagement positively influences an employee's identification with the employing organization, and their perception of doing meaningful work, employees tend to work harder and longer and are more unwilling to disengage from work activities. This represents a positive effect of CSR on work addiction, which can buffer or perhaps even outweigh the in principle negative effect of CSR activities on work addiction. Work addiction and its potential negative consequences are common and severe problems in organizations, and it is thus no surprise that great effort is made to address these problems (Burke 2009).

It is thus important for organizations to realize that CSR can, while having many positive effects on employees, also cause certain negative effects; in this case, an increase in the risk of work addiction. Organizations should therefore be aware of, and actively manage, the risk of work addiction associated with CSR. By acknowledging that perceived CSR engagement positively influences work addiction through more organizational identification and work meaningfulness, organizations might be able to develop more effective mitigation strategies.

One strategy might be to help employees identify and prioritize their individual and private needs, such as staying healthy and maintaining functioning relationships. If employees realize that the fulfillment of these needs is an additional source of meaning and identity, or at least a precondition for fulfilled work, they might be less likely to become addicted to work. Organizations could achieve this through targeted training programs and coaching, together with systemic measures such as flexible work hours. Moreover, they could also ensure that leaders role-model the desired behavior and actively support their employees. Previous research findings indicate that greater organizational support for work-life balance reduces workaholic job behaviors (Burke 2001). In addition, leaders could try to increasingly align their organization's CSR activities with their core business, instead of overly engaging in CSR activities that are merely additional, symbolic, or compensatory. Focusing on and creating awareness for the societal contributions an organization makes through its core activities might help leaders and employees achieve a similar alignment on the individual level, so that an individual can be sure that diligently completing their own day-to-day tasks-while staying healthy and productive-is a sufficient contribution to the common good.

Additional implications result from the fact that the effects of CSR on work meaningfulness and organizational identification seem to be stronger for employees with higher public value awareness. Those employees that show high consideration for the impact of their actions on their communities, their nation, and the world as a whole, seem to be more likely to derive a sense of meaning and identity from their organization's perceived CSR activities. As a result, they are more likely to become addicted to work. This means that on one hand, organizations can invest in increasing their employees' public value awareness to increase the impact of their CSR practices on meaningfulness and organizational identification. On the other hand, organizations should be aware that those employees with high degrees of public value awareness may be in special need of the mitigation approaches described above. In any case, approaches and tools for understanding and influencing public value awareness, as well as the meaningfulness and organizational identification of individuals, should be developed and deployed to effectively mitigate the risk of work addiction.

\section{Contributions, Limitations, and Future Research}

Our study offers two main contributions. First, our research significantly adds to the CSR literature by answering calls to focus on the individual level of analysis, i.e., how the employee perceives organizational CSR endeavors, and how this impacts individual-level outcomes (Aguinis and Glavas 2017; Glavas and Kelley 2014). By exploring potential moderators and mediators of the CSR-outcome relationship, our study extends and refines recent studies analyzing the impact of CSR. We provide a more contextualized understanding of the conditions by which CSR shapes employee attitudes, intentions, and behaviors, and we also point to the different effects of organizational CSR activities. Thus, an important implication of our study is the need to view CSR through dual lenses of value creation and occupation. While we focused on the risk of work addiction (and consequent self-sacrifice), future research should embrace all potential downsides and risks of CSR, including those suggested previously (stagnation and self-righteousness).

Second, we contribute to the broader management literature by examining how employee perceptions of CSR are related to employee work addiction and its underlying mechanisms. Evidence for the role of moderator and mediator variables in the relationship between an organization's CSR engagement and employee work addiction remains inconclusive. By broadening the theoretical framework, we empirically substantiate the idea that employee work addiction is 
not the product of a single source, but rather a result of a complex interplay of variables and constructs that remain underexplored. Our results may stimulate other researchers aiming to understand the interplay between organizational actions directed towards society and individual-level outcomes. Moreover, our research results indicate that the respective variables should not be studied in isolation.

However, our findings should be considered in light of several limitations that may constrain the generalizability of the results. One limitation is the cross-sectional design of our study, which does not allow causal relationships among the variables to be determined; this fact may limit the validity of our findings. In order to account for the dynamic nature of certain variables - such as work addiction or perceived corporate social responsibility-a longitudinal design would be preferable to a cross-sectional design.

An additional limitation is one that is prevalent in behavioral sciences (Podsakoff et al. 2003): the potential of systematic error variance in the form of common method bias. We took steps that partially mitigate this limitation. First, to reduce the risk of socially desirable responses, respondents were promised anonymity and were not asked to provide the name of their employing organization. Also, as recommended by Podsakoff et al. (2003), we varied the response formats for predictor and criterion measures, and added a number of reverse-coded items and open questions to the survey. To reduce complexity, only a limited number of items were displayed on the screen at a time. Additionally, prior to data collection, we pretested item comprehensibility and study length by collecting qualitative and quantitative feedback. Furthermore, we added a number of control variables in order to detect shared aspects in cognition and thus differences in response bias across groups (Meynhardt et al. 2018). The fact that our survey items were part of a largescale questionnaire decreases the risk of respondents being able to guess the study objectives, thereby fostering response consistency (Mohr and Spekman 1994). In addition, our results did not reveal any response patterns. Consequently, we believe that common method bias does not significantly influence the results of our study.

Finally, the scope of this study was limited to Switzerland. According to the OECD Better Life Index (2017), people in Switzerland are generally more satisfied with their lives and their jobs compared to the OECD average. Moreover, the mean level of work addiction in the Swiss sample is 2.49 , reflecting a generally modest level of workaholism. Further studies need to be carried out in other countries in order to validate these results. Despite these limitations, we believe our conclusions are reasonable and consistent with prior research. We are confident that other researchers can take advantage of our empirical results to understand how organizational CSR activities change employee work attitudes and behavior.
Acknowledgements The authors would like to thank the section editor Charlotte M. Karam and two anonymous reviewers for their very helpful comments, criticism, and suggestions. Stefan Anderer wants to thank the Friede Springer Foundation for the financial support of his research.

\section{Compliance with Ethical Standards}

Conflict of interest All five co-authors declare that they have no conflict of interest.

Open Access This article is distributed under the terms of the Creative Commons Attribution 4.0 International License (http://creativeco mmons.org/licenses/by/4.0/), which permits unrestricted use, distribution, and reproduction in any medium, provided you give appropriate credit to the original author(s) and the source, provide a link to the Creative Commons license, and indicate if changes were made.

\section{References}

Abele, A. E., Volmer, J., \& Spurk, D. (2012). Career stagnation: Underlying dilemmas and solutions in contemporary work environments. In N. P. Reilly, M. J. Sirgy, \& C. A. Gorman (Eds.), Work and quality of life (pp. 107-132). Dordrecht: Springer.

Aguilera, R. V., Rupp, D. E., Williams, C. A., \& Ganapathi, J. (2007). Putting the $\mathrm{S}$ back in corporate social responsibility: A multilevel theory of social change in organizations. Academy of Management Review, 32(3), 836-863.

Aguinis, H., \& Glavas, A. (2012). What we know and don't know about corporate social responsibility: A review and research agenda. Journal of Management, 38, 932-968.

Aguinis, H., \& Glavas, A. (2017). On corporate social responsibility, sensemaking, and the search for meaningfulness through work. Journal of Management, 42, 507-525.

Andreassen, C. S. (2013). Workaholism: An overview and current status of the research. Journal of Behavioral Addictions, 3(1), 1-11.

Andreassen, C. S., Griffiths, M. D., Hetland, J., Kravina, L., Jensen, F., \& Pallesen, S. (2014). The prevalence of workaholism: A survey study in a nationally representative sample of Norwegian employees. PLOS ONE, 9(8), 1-10.

Andreassen, C. S., Griffiths, M. D., Hetland, J., \& Pallesen, S. (2012). Development of a work addiction scale. Scandinavian Journal of Psychology, 53, 265-272.

Andreassen, C. S., Hetland, J., \& Pallesen, S. (2010). The relationship between 'workaholism', basic needs satisfaction at work and personality. European Journal of Personality, 24(1), 3-17.

Ashforth, B. E., \& Mael, F. (1989). Social identity theory and the organization. Academy of Management Review, 14(1), 20-39.

Avanzi, L., van Dick, R., Fraccaroli, F., \& Sarchielli, G. (2012). The downside of organizational identification: Relations between identification, workaholism and well-being. Work \& Stress, 26(3), 289-307.

Banerjee, S. B. (2008). Corporate social responsibility: The good, the bad and the ugly. Critical Sociology, 34(1), 51-79.

Barnett, M. L. (2016). The business case for corporate social responsibility: A critique and an indirect path forward. Business \& Society, 58(1), 167-190.

Blader, S. L., \& Tyler, T. R. (2009). Testing and extending the group engagement model: Linkages between social identity, procedural justice, economic outcomes, and extrarole behavior. Journal of Applied Psychology, 94(2), 445-464. 
Blanken, I., van de Ven, N., \& Zeelenberg, M. (2015). A meta-analytic review of moral licensing. Personality and Social Psychology Bulletin, 41(4), 540-558.

Blasco, J. L., \& King, A. (2017). The road ahead: the KPMG survey of corporate responsibility reporting 2017. Zurich: KPMG International. Retrieved November 20, 2018 from http://www. home.kpmg/content/dam/kpmg/campaigns/csr/pdf/CSR_Repor ting_2017.pdf.

Bocquet, R., Le Bas, C., Mothe, C., \& Poussing, N. (2013). Are firms with different CSR profiles equally innovative? Empirical analysis with survey data. European Management Journal, 31(6), 642-654.

Bocquet, R., Le Bas, C., Mothe, C., \& Poussing, N. (2017). CSR, innovation, and firm performance in sluggish growth contexts: A firm-level empirical analysis. Journal of Business Ethics, 146(1), 241-254.

Boxx, W. R., Odom, R. Y., \& Dunn, M. G. (1991). Organizational values and value congruency and their impact on satisfaction, commitment, and cohesion: An empirical examination within the public sector. Public Personnel Management, 20(2), 195-205.

Brammer, S., He, H. W., \& Mellahi, K. (2015). Corporate social responsibility, employee organizational identification, and creative effort: The moderating impact of corporate ability. Group \& Organization Management, 40(3), 323-352.

Brammer, S., Millington, A., \& Rayton, B. (2007). The contribution of corporate social responsibility to organizational commitment. The International Journal of Human Resource Management, 18(10), 1701-1719.

Brieger, S. A. (2018). Social identity and environmental concern: The importance of contextual effects. Environment and Behavior. https://doi.org/10.1177/0013916518756988.

Brieger, S. A., Terjesen, S. A., Hechavarría, D. M., \& Welzel, C. (2018). Prosociality in business: A human empowerment framework. Journal of Business Ethics. https://doi.org/10.1007/s1055 1-018-4045-5.

Burke, R. J. (2000). Workaholism in organizations: Psychological and physical well-being consequences. Stress Medicine, 16(1), $11-16$.

Burke, R. J. (2001). Workaholism in organizations: The role of organizational values. Personnel Review, 30(5-6), 637-645.

Burke, R. J. (2001). Predictors of workaholism components and behaviors. International Journal of Stress Management, 8(2), 113-127.

Burke, R. J. (2009). Working to live or living to work: Should individuals and organizations care? Journal of Business Ethics, 84, $167-172$.

Burke, R. J., \& Fiksenbaum, L. (2009). Work motivations, work outcomes, and health: Passion versus addiction. Journal of Business Ethics, 84, 257-263.

Caesens, G., Stinglhamber, F., \& Luypaert, G. (2014). The impact of work engagement and workaholism on well-being: The role of work-related social support. Career Development International, 19(7), 813-835.

Carroll, J. J., \& Robinson, B. E. (2000). Depression and parentification among adults as related to parental workaholism and alcoholism. The Family Journal, 8(4), 360-367.

Chatman, J. A., \& Cha, S. E. (2003). Leading by leveraging culture. California Management Review, 45(4), 20-34.

CLVS. (2017). GemeinwohlAtlas: Der gesellschaftliche Nutzen von Schweizer und internationalen Unternehmen und Organisationen systematisch untersucht und transparent abgebildet. Retrieved November 20, 2018 from http://www.gemeinwohl.ch/en.

Costas, J., \& Kärreman, D. (2013). Conscience as control-managing employees through CSR. Organization, 20(3), 394-415.

Cropanzano, R., \& Rupp, D. E. (2008). Social exchange theory and organizational justice: Job performance, citizenship behaviors, multiple foci, and a historical integration of two literatures. In S.
W. Gilliland, D. P. Skarlicki, \& D. D. Steiner (Eds.), Research in social issues in management (pp. 63-99). Greenwich: Information Age Publishing.

Dawkins, C. E., Jamali, D., Karam, C., Lin, L., \& Zhao, J. (2016). Corporate social responsibility and job choice intentions: A crosscultural analysis. Business \& Society, 55(6), 854-888.

De Roeck, K., \& Delobbe, N. (2012). Do environmental CSR initiatives serve organizations' legitimacy in the oil industry? Exploring employees' reactions through organizational identification theory. Journal of Business Ethics, 110(4), 397-412.

Deci, E. L., \& Ryan, R. M. (2000). The "what" and "why" of goal pursuits: Human needs and the self-determination of behavior. Psychological Inquiry, 11(4), 227-268.

Delmas, M. A., \& Burbano, V. C. (2011). The drivers of greenwashing. California Management Review, 54(1), 64-87.

Dempsey, S. E., \& Sanders, M. L. (2010). Meaningful work? Nonprofit marketization and work/life imbalance in popular autobiographies of social entrepreneurship. Organization, 17(4), 437-459.

Doerfler, M. C., \& Kammer, P. P. (1986). Workaholism, sex, and sex role stereotyping among female professionals. Sex Roles, 14(9), $551-560$.

Du, S. L., Bhattacharya, C. B., \& Sen, S. (2015). Corporate social responsibility, multi-faceted job-products, and employee outcomes. Journal of Business Ethics, 131(2), 319-335.

Duffy, B. E. (2016). The romance of work: Gender and aspirational labour in the digital culture industries. International Journal of Cultural Studies, 19(4), 441-457.

European Commission (2001). Promoting a European framework for corporate social responsibility, green paper. Luxembourg: European Commission, Directorate-General for Employment and Social Affairs.

Farooq, O., Payaud, M., Merunka, D., \& Valette-Florence, P. (2014). The impact of corporate social responsibility on organizational commitment: Exploring multiple mediation mechanisms. Journal of Business Ethics, 125(4), 563-580.

Farooq, O., Rupp, D. E., \& Farooq, M. (2017). The multiple pathways through which internal and external corporate social responsibility influence organizational identification and multifoci outcomes: The moderating role of cultural and social orientations. Academy of Management Journal, 60(3), 954-985.

Flammer, C. (2015). Does corporate social responsibility lead to superior financial performance? A regression discontinuity approach. Management Science, 61(11), 2549-2568.

Glavas, A., \& Godwin, L. N. (2013). Is the perception of 'goodness' good enough? Exploring the relationship between perceived corporate social responsibility and employee organizational identification. Journal of Business Ethics, 114(1), 15-27.

Glavas, A., \& Kelley, K. (2014). The effects of perceived corporate social responsibility on employee attitudes. Business Ethics Quarterly, 24(2), 165-202.

Glavas, A., \& Piderit, S. K. (2009). How does doing good matter? Effects of corporate citizenship on employees. Journal of Corporate Citizenship, 36, 51-70.

Hackman, J. R., \& Oldham, G. R. (1980). Work redesign. Reading: Addison-Wesley.

Hansen, S. D., Dunford, B. B., Boss, A. D., Boss, R. W., \& Angermeier, I. (2011). Corporate social responsibility and the benefits of employee trust: A cross-disciplinary perspective. Journal of Business Ethics, 102(1), 29-45.

Haski-Leventhal, D., \& Concato, J. (2016). The state of CSR and RME in business schools and the attitudes of their students. Third biannual study. PRME initiative. Retrieved November 20, 2018 from http://www.unprme.org/resource-docs/MGSMPRMERe port2016.pdf. 
Hörisch, J., Kollat, J., \& Brieger, S. A. (2017). What influences environmental entrepreneurship? A multilevel analysis of the determinants of entrepreneurs' environmental orientation. Small Business Economics, 48(1), 47-69.

Jamali, D., \& Karam, C. (2018). Corporate social responsibility in developing countries as an emerging field of study. International Journal of Management Reviews, 20(1), 32-61.

Jayasinghe, M. (2016). The operational and signaling benefits of voluntary labor code adoption: Reconceptualizing the scope of human resource management in emerging economies. Academy of Management Journal, 59(2), 658-677.

Kaplan, R., \& Kinderman, D. (2017). The business-led globalization of CSR: Channels of diffusion from the United States into Venezuela and Britain, 1962-1981. Business \& Society. https://doi. org/10.1177/0007650317717958.

Kim, H. R., Lee, M., Lee, H. T., \& Kim, N. M. (2010). Corporate social responsibility and employee-company identification. Journal of Business Ethics, 95(4), 557-569.

Kinderman, D. (2011). 'Free us up so we can be responsible!' The coevolution of Corporate Social Responsibility and neo-liberalism in the UK, 1977-2010. Socio-Economic Review, 10(1), 29-57.

Kirchgeorg, M., Meynhardt, T., Pinkwart, A., Suchanek, A., \& Zülch, H. (2017). Das Leipziger Führungsmodell: The Leipzig leadership model. Indianapolis: BoD—Books on Demand.

Kreiner, G. E., Hollensbe, E. C., \& Sheep, M. L. (2006). Where is the "me" among the "we"? Identity work and the search for optimal balance. Academy of Management Journal, 49(5), $1031-1057$

Kubota, K., Shimazu, A., Kawakami, N., Takahashi, M., Nakata, A., \& Schaufeli, W. B. (2010). Association between workaholism and sleep problems among hospital nurses. Industrial Health, 48(6), 864-871.

Lin, C. P., Baruch, Y., \& Shih, W. C. (2012). Corporate social responsibility and team performance: The mediating role of team efficacy and team self-esteem. Journal of Business Ethics, 108(2), 167-180.

Lin-Hi, N., \& Müller, K. (2013). The CSR bottom line: Preventing corporate social irresponsibility. Journal of Business Research, 66(10), 1928-1936.

Machlowitz, M. (1980). Workaholics: Living with them, working with them. Reading: Addison-Wesley.

Maes, K. (2012). Volunteerism or labor exploitation? Harnessing the volunteer spirit to sustain AIDS treatment programs in urban Ethiopia. Human Organization, 71(1), 54-64.

Makni, R., Francoeur, C., \& Bellavance, F. (2009). Causality between corporate social performance and financial performance: Evidence from Canadian firms. Journal of Business Ethics, 89(3), 409-422.

Matsudaira, K., Shimazu, A., Fujii, T., Kubota, K., Sawada, T., Kikuchi, N., \& Takahashi, M. (2013). Workaholism as a risk factor for depressive mood, disabling back pain, and sickness absence. Plos One, 8(9), 1-8.

May, D. R., Gilson, R. L., \& Harter, L. M. (2004). The psychological conditions of meaningfulness, safety and availability and the engagement of the human spirit at work. Journal of Occupational and Organizational Psychology, 77(1), 11-37.

McWilliams, A., \& Siegel, D. (2001). Corporate social responsibility: A theory of the firm perspective. Academy of Management Review, 26(1), 117-127.

Meynhardt, T. (2009). Public value inside: What is public value creation? International Journal of Public Administration, 32(3-4), 192-219.

Meynhardt, T., Brieger, S. A., \& Hermann, C. (2018). Organizational public value and employee life satisfaction: The mediating roles of work engagement and organizational citizenship behavior. The
International Journal of Human Resource Management. https:// doi.org/10.1080/09585192.2017.1416653.

Meynhardt, T., Brieger, S. A., Strathoff, P., Anderer, S., Bäro, A., Hermann, C., Kollat, J., Neumann, J., Bartholomes, S., \& Gomez, P. (2017). Public value performance: What does it mean to create value in the public sector? In R. Andeßner, D. Greiling, \& R. Vogel (Eds.), Public sector management in a globalized world (pp. 135-160). Wiesbaden: Springer Gabler.

Meynhardt, T., \& Fröhlich, A. (2019). More value awareness for more (public) value: Recognizing how and for who value truly is created. In A. Lindgreen, N. Koenig-Lewis, M. Kitchener, J. Brewer, M. H. Moore, \& T. Meynhardt (Eds.), Public value: Deepening, enriching, and broadening the theory and practice. Oxford: Routledge

Meynhardt, T., \& Gomez, P. (2016). Building blocks for alternative four-dimensional pyramids of corporate social responsibilities. Business \& Society. https://doi.org/10.1177/0007650316650444.

Mittal, R., Sinha, N., \& Singh, A. (2008). An analysis of linkage between economic value added and corporate social responsibility. Management Decision, 46(9), 1437-1443.

Mohr, J., \& Spekman, R. (1994). Characteristics of partnership success: Partnership attributes, communication behavior, and conflict resolution techniques. Strategic Management Journal, 15(2), $135-152$.

Mullen, E., \& Monin, B. (2016). Consistency versus licensing effects of past moral behavior. Annual Review of Psychology, 67, 363-385.

Newman, A., Nielsen, I., \& Miao, Q. (2015). The impact of employee perceptions of organizational corporate social responsibility practices on job performance and organizational citizenship behavior: Evidence from the Chinese private sector. International Journal of Human Resource Management, 26(9), 1226-1242.

Nunnally, J.C. (1978). Psychometric theory. New York, NY: McGraw-Hill.

Nyborg, K., \& Zhang, T. (2013). Is corporate social responsibility associated with lower wages? Environmental and Resource Economics, 55(1), 107-117.

Oates, W. E. (1971). Confessions of a workaholic: The facts about work addiction. New York: World.

OECD. (2017). How's life? 2017: Measuring well-being. Paris: OECD Publishing.

Ormiston, M. E., \& Wong, E. M. (2013). License to ill: The effects of corporate social responsibility and CEO moral identity on corporate social irresponsibility. Personnel Psychology, 66(4), 861-893.

Perez-Batres, L. A., Doh, J. P., Miller, V. V., \& Pisani, M. J. (2012). Stakeholder pressures as determinants of CSR strategic choice: Why do firms choose symbolic versus substantive self-regulatory codes of conduct? Journal of Business Ethics, 110(2), 157-172.

Podsakoff, P. M., MacKenzie, S. B., Lee, J.-Y., \& Podsakoff, N. P. (2003). Common method biases in behavioral research: A critical review of the literature and recommended remedies. The Journal of Applied Psychology, 88(5), 879-903.

Porter, G. (1996). Organizational impact of workaholism: Suggestions for researching the negative outcomes of excessive work. Journal of Occupational Health Psychology, 1, 70-84.

Preuss, L. (2012). Responsibility in paradise? The adoption of CSR tools by companies domiciled in tax havens. Journal of Business Ethics, 110(1), 1-14.

Robinson, B. E., Fowers, C., \& Carroll, J. (2001). Work stress and marriage: A theoretical model examining the relationship between workaholism and marital cohesion. International Journal of Stress Management, 8(2), 165-175.

Roh, C. Y., Moon, M. J., Yang, S. B., \& Jung, K. (2016). Linking emotional labor, public service motivation, and job satisfaction: Social workers in health care settings. Social Work in Public Health, 31(2), 43-57. 
Rosso, B. D., Dekas, K. H., \& Wrzesniewski, A. (2010). On the meaning of work: A theoretical integration and review. Research in Organizational Behavior, 30, 91-127.

Rupp, D. E., \& Mallory, D. B. (2015). Corporate social responsibility: Psychological, person-centric, and progressing. Annual Review of Organizational Psychology and Organizational Behavior, 2(1), 211-236.

Ryan, R. M., \& Deci, E. L. (2000). Intrinsic and extrinsic motivations: Classic definitions and new directions. Contemporary educational psychology, 25(1), 54-67.

Sachdeva, S., Iliev, R., \& Medin, D. L. (2009). Sinning saints and saintly sinners: The paradox of moral self-regulation. Psychological Science, 20(4), 523-528.

Schabracq, M. J., Winnubst, J. A., \& Cooper, C. L. (Eds.). (2003). The handbook of work and health psychology. Chichester: Wiley.

Schaltegger, S., \& Hörisch, J. (2017). In search of the dominant rationale in sustainability management: Legitimacy-or profit-seeking? Journal of Business Ethics, 145(2), 259-276.

Schaufeli, W. B., Shimazu, A., \& Taris, T. W. (2009). Being driven to work excessively hard. The evaluation of a two-factor measure of workaholism in the Netherlands and Japan. Cross-Cultural Research, 43(4), 320-348.

Schaufeli, W. B., \& Taris, T. W. (2014). A critical review of the job demands-resources model: Implications for improving work and health. In G. F. Bauer \& O. Hämmig (Eds.), Bridging occupational, organizational and public health (pp. 43-68). Dordrecht: Springer.

Spreitzer, G. M. (1995). Psychological empowerment in the workplace: Dimensions, measurement, and validation. Academy of Management Journal, 38(5), 1442-1465.

Sussman, S. (2012). Workaholism: A review. Journal of Addiction Research \& Therapy, 6(1), 4120.
Sussman, S., Lisha, N., \& Griffiths, M. (2011). Prevalence of the addictions: A problem of the majority or the minority? Evaluation \& the Health Professions, 34(1), 3-56.

Swann, W. B. Jr., Buhrmester, M. D., Gómez, A., Jetten, J., Bastian, B., Vázquez, A., ... \& Finchilescu, G. (2014). What makes a group worth dying for? Identity fusion fosters perception of familial ties, promoting self-sacrifice. Journal of Personality and Social Psychology, 106(6), 912.

Tajfel, H., \& Turner, J. C. (1986). The social identity theory of intergroup behavior. In S. Worchel \& W. G. Austin (Eds.), Psychology of intergroup relations (pp. 7-24). Chicago: Nelson-Hall.

Taris, T. W., Van Beek, I., \& Schaufeli, W. B. (2012). Demographic and occupational correlates of workaholism. Psychological Reports, $110(2), 547-554$.

Tokumitsu, M. (2015). Do what you love: And other lies about success \& happiness. New York: Regan Arts.

van Beek, I., Taris, T. W., \& Schaufeli, W. B. (2011). Workaholic and work engaged employees: Dead ringers or worlds apart? Journal of Occupational Health Psychology, 16(4), 468-482.

Wrzesniewski, A. (2003). Finding positive meaning in work. In K. S. Cameron, J. E. Dutton, \& R. E. Quinn (Eds.), Positive organizational scholarship: Foundations of a new discipline (pp. 296308). San Francisco: Berrett-Koehler.

Yamaha Corporation. (2017). Promoting Work-Life Balance. Retrieved November 20, 2018 from https://www.yamaha.com/en/csr/ human_rights_and_labor_practices/worklife_balance/.

Publisher's Note Springer Nature remains neutral with regard to jurisdictional claims in published maps and institutional affiliations. 